\title{
Rodríguez Gallardo, Adolfo. (2015) José Vasconcelos: alfabetización, bibliotecas, lectura y edición. México: UNAM.
}

\section{Jorge A. Muñoz Figueroa}

"¿Por qué otro libro sobre José Vasconcelos?" La pregunta no es mía y, sin embargo, me la apropié cuando tuve entre mis manos un ejemplar de José Vasconcelos: alfabetización, bibliotecas, lectura y edición, publicado hacia finales de 2015. El mismo autor, el doctor Adolfo Rodríguez Gallardo, anticipa la pregunta del lector y responde con claridad:

La diferencia entre esta obra, y otras sobre el tema, es que ésta aborda conjuntamente el pensamiento de Vasconcelos y su relación con los programas que promovió. Para conocer sus ideas sobre la importancia de la lectura y la biblioteca, así como la influencia que tuvieron en sus acciones públicas se utilizaron, primordialmente, sus novelas autobiográficas, conferencias y ensayos; para entender la labor que realizó en favor de los programas que impulsó, las publicaciones oficiales que dieron cuenta de su labor en la Universidad Nacional de México y en la SEP, entre ellas, el Boletín de la Universidad, el Boletín de la Secretaría de Educación Pública, El libro y el pueblo y El maestro (7).

Así, desde las primeras líneas de su investigación, Rodríguez Gallardo deja claros sus pretextos y sus pre-textos: los primeros (las ideas de Vasconcelos), son los ejes que soportan su obra, el andamiaje sobre el que montará los segundos, los documentos de los que se valió para registrar, puntualmente, las acciones resultantes de sus motivaciones. Tamaña labor implica, como lo intuye el lector de estas líneas, un trabajo arduo y apasionado, moroso y amoroso sin duda. Para acometer semejante tarea, es imprescindible estar contagiado de ese espíritu propio del maestro Vasconcelos. Y uno de los académicos eméritos de la UNAM, como el doctor Adolfo Rodríguez, puede presumir de ello.

Por supuesto, a la par de lo anterior, se registran las nociones de las bibliotecas como espacios formativos, de lo cual se tienen noticias en buena parte del texto. Además, encuentro algunas frases contundentes que aparecen en distintos momentos de la investigación; frases que si bien retoman el pensamiento de Vasconcelos, Rodríguez Gallardo las tiene perfectamente claras en su quehacer universitario. Aquí un ejemplo apenas inicia el capítulo uno:

En esa ocasión plantea [Vasconcelos] que el Estado debe intentar cerrar la brecha del conocimiento: "[...] no puedo dejar de creer que un Estado, cualquiera que él sea, que permite que subsista el contraste del absoluto 
desamparo con la sabiduría intensa o la riqueza extrema, es un Estado injusto, cruel y rematadamente bárbaro" (15)

Y para acompañar esta frase, el autor del libro puntualiza: "[...] para Vasconcelos educar noes sólo una actividad necesaria, sino un imperativo moral que permitiría al país eliminar la injusticia y la inequidad entre los ciudadanos". Recordarnos esta frase en un libro que sirve como caja de resonancia y amplificador, nos obliga a atenderla en la medida de nuestras posibilidades dado el contexto actual nacional e internacional. Si no nos sentimos tocados por este "imperativo moral", algo estamos haciendo mal.

Líneas atrás señalé que esta investigación es un trabajo moroso y amoroso, pues la consulta y el registro de la abundante bibliografía, de las imágenes que acompañan algunos pasajes, pero sobre todo, de los generosos anexos que permiten dimensionar la minuciosa y puntual tarea que llevó a cabo el autor, nos habla de una paciente dedicación que conlleva no poca pasión por el proyecto de Vasconcelos. De ello dan cuenta, para empezar, el Prefacio y la Introducción, y la tónica se mantiene en los cuatro capítulos que documentan con detalle y claridad "La lectura" y "Las bibliotecas" en el primero titulado "Pensamiento"; en el segundo, Rodríguez Gallardo aborda la "Alfabetización", para entrar en el terreno de las "Publicaciones" y de todo lo relacionado con las "Bibliotecas" en los capítulos tres y cuatro, respectivamente. Deseo destacar aspectos concretos que me resultan muy sugerentes de su trabajo en los primeros dos capítulos.

El primero de ellos es la formación de José Vasconcelos como lector, de la cual nos habla Rodríguez Gallardo en el apartado "La lectura” y lo registra desde los primeros recuerdos que consigna Vasconcelos en el volumen que inaugura sus memorias: Ulises criollo; en dicho título encontramos las dos grandes influencias de su infancia lectora: su hogar y la escuela. Mientras que en casa su madre orienta con rigor sus gustos, evitando los "libros herejes", en su escuela norteamericana entrará en contacto con los clásicos de la literatura, pero sobre todo, lo que impactará al joven José es algo muy cotidiano para nosotros desde hace décadas y que debemos a las acciones del Maestro de la juventud de América: el préstamo a domicilio. Detalle que podría parecernos menor, pero que significó toda una revolución emprendida por Vasconcelos en un programa integral, tal como lo explica Rodríguez Gallardo, quien párrafos más adelante nos recuerda una imagen clásica de Vasconcelos creada por el propio autor de Ulises criollo: "El niño Vasconcelos adquiere madurez desde la infancia debido a su gusto por la lectura, la cual es parte esencial en la formación de su carácter, como se trasluce en la emoción, el interés y el entusiasmo con que describe lo que significó la lectura en su vida [...] Su soberbia aumenta porque se considera el niño que más ha leído. Esta soberbia tiene su base en el intelecto y es reforzada y cultivada cuidadosamente mediante la lectura, tanto en casa como 
en la escuela" (21-22). Así, Rodríguez Gallardo hace un detallado seguimiento de las impresiones que tiene Vasconcelos sobre la lectura, mismas que no se limitan a Ulises criollo, sino que da cuenta de lo que opina el maestro en los otros tomos de sus memorias, prueba de ello es lo que comenta y cita de EI desastre: "Vasconcelos piensa que mediante la lectura las personas enriquecen su personalidad, su cultura y, en general, su educación; no obstante, también considera que 'No bastan los libros; no es suficiente la reflexión solitaria; el que tiene que producir necesita el trato del prójimo"' (28). De igual manera, Rodríguez cita una opinión de El proconsulado: "Para empezar, proclamemos que el fanatismo se combate con libros, no con ametralladoras [...] toca al Estado mediar en los conflictos de todos los fanatismos en vez de abrazarse a uno de ellos" (29). Dado lo anterior, Rodríguez explica: "Aquí es significativo detenerse y analizar la importancia del plural usado por Vasconcelos, ya que su deseo es combatir el fanatismo con libros, sean éstos editados o utilizados en las bibliotecas, pero principalmente leídos. El conocimiento, entonces, no se encuentra en una sola obra por importante que ésta sea" (29).

Acertadamente señala Rodríguez Gallardo que la formación que gozó Vasconcelos en Piedras Negras, primero, y en Campeche después, forjaron a un lector aguerrido, soberbio y lleno de aspiraciones. Quizá agregaría un matiz en este punto: tal como el autor lo indica, una de las fuentes que tenemos para informarnos del camino iniciático del joven Pepe (o Joe, como le decían en su escuela tejana) es su propia narrativa, la cual se ve desbordada por la ficcionalización que hace con su persona; es decir, Vasconcelos, pese a su intento de decir la verdad (su verdad), no resiste a la posibilidad de crear un personaje de sí mismo, máxime si consideramos sus memorias como un acto político en el cual, además de reivindicarse, se reinserta en el campo cultural luego del desprestigio del que ha sido víctima. Y qué mejor que proyectarse desde la infancia como un ser elegido y llamado a dirigir masas.

El segundo aspecto en el que me quiero enfocar brevemente es en el convencimiento de Vasconcelos en la alfabetización, pues las bibliotecas por sí solas no tendrían sentido; la apuesta y el empeño en tal empresa es de todos conocida y estupendamente bien documentada por Rodríguez Gallardo, quien, mediante los ejemplos, los anexos y demás apoyos que incluye en su libro para explicarnos el proyecto integral del maestro, sostiene otra frase contundente que desliza sin demasiados aspavientos, pero de manera muy efectiva: "Si sus ideas hubieran continuado, hoy en día México contaría con un sistema bibliotecario más robusto" (35). Y agrega: "Posiblemente la claridad del papel que las bibliotecas tienen en la educación y en la difusión de la cultura, como elementos básicos en el mejoramiento educativo y cultural de los niños y de los 
adultos, no ha sido comprendido con tal claridad por ningún otro secretario de Educación" (36).

No deseo minimizar la importancia de la educación de los adultos, pero me detengo en el énfasis que Vasconcelos siempre tuvo para la educación de los niños, tal como lo consigna en diversas ocasiones Rodríguez Gallardo en su libro, y que hace eco con otro elemento relevante, una lectura incluida en alguna de las listas que nos proporciona en anexos el trabajo del investigador emérito de la UNAM: se trata de Emilio, de Rousseau (1762). Resulta este título un texto capital en la noción moderna del niño en Occidente, y aunque a Vasconcelos no le atrajo tanto por su estilo novelado, no se puede negar su influencia en algunas ideas que el propio Secretario tendría, como el cambio de paradigma que ya estaba en boga en Occidente sobre el niño como ente social. Este significativo cambio, de pensar al niño como ente inocente y sin capacidad de elección a considerarlo un objeto pedagógico específico y darle un sitio distinto en la sociedad y en el núcleo familiar a partir de las ideas de Rousseau, se refleja en algunas ideas que Vasconcelos tiene no sólo sobre el niño, sino sobre el pueblo al que quiere alfabetizar. Transcribo y leo una cita de Vasconcelos que aparece en el libro de Rodríguez Gallardo: "Y quienes creen que tales libros no interesan a las masas, no saben lo que son las masas ni han observado una biblioteca pública [...] ¿Qué condena de infantilismo o de idiotez pesa sobre nuestra gente que, por excepción entre todas las de la tierra, no se le quiere reconocer la capacidad de gustar lo clásico" (57).

Interesantes palabras que niegan que "nuestra gente" permanezca en una especie de "infancia” y así, haciendo eco de las ideas del filósofo francés, dan un peso específico a la educación de los niños mexicanos.

En este breve texto resulta difícil enlistar otros aportes del libro José Vasconcelos: alfabetización, bibliotecas, lectura y edición. Me resta reconocer al doctor Adolfo Rodríguez Gallardo por tan generoso libro, el cual se antoja como punto de partida para investigaciones que deseen profundizar en la trayectoria de José Vasconcelos. Este libro, ya sea leído a veces de pie o a veces sentado, invita a repasar uno de los periodos claves en la conformación de nuestras instituciones culturales. 